SAND93-1138

Unlimited Release

Printed September 1993

Distribution
Category UC -704

\title{
Laser Soldering of Sn Plated Brass Integrator Assembly Housings
}

\author{
D. M. Keicher \\ Physical and Joining Metallurgy Department \\ G. A. Poulter and N. R. Sorensen \\ Mechanical and Corrosion Metallurgy Department \\ Sandia National Laboratories \\ Albuquerque, New Mexico 87185
}

\begin{abstract}
The high conductivity provided by solder closure joints of component housings is sometimes required to ensure electrical shielding of the components contained within. However, using a soldering iron to produce the solder joints can lead to charring of the insulating materials within the housing. To overcome this problem, the localized heating characteristics of laser soldering can be exploited. The feasibility of laser soldering $\mathrm{Sn}$ plated brass housings with a CW Nd:YAG laser has been investigated. It has been determined that laser soldering of these housings using a low solids solder flux is a viable technique and will minimize the amount of heat input to the enclosed electronic components. Metallographic analysis has shown good wetting of the solder on the housing components. Accelerated aging experiments indicate that no significant corrosion potential due to solder flux residues exists. Although a low solids flux was used to make the joints, initial results indicate that a fluxless technique can be developed to eliminate fluxes completely.
\end{abstract}




\section{LASER SOLDERING OF Sn PLATED BRASS INTEGRATOR ASSEMBLY HOUSINGS}

\section{Introduction}

Experiments were performed to determine the feasibility of laser soldering Integrator Assembly, Main 395895 housings to minimize electrical noise. Laser soldering of the housing assembly was proposed since the process could produce the desired electrical properties provided by a soldered closure joint. The energy provided by a Nd:YAG laser is readily absorbed by the $\mathrm{Sn}$ plating on the brass housing and produces localized, efficient heating. This allows the high thermal diffusivity of the brass material to be eliminated as a factor since the total heat input to the component will be minimized. A fluxless laser soldering process for Au plated Kovar has been previously developed[1]. Thus, soldering of these housings without flux as well as with a low solids flux was explored.

\section{Experimental}

Three empty housings and one housing containing electrical components were provided to perform these experiments. As a heat source, a CW Nd:YAG laser with a fundamental wavelength at $1.064 \mu \mathrm{m}$ operating at an output power of 64 watts was used. A schematic representation of the experimental apparatus is given in Figure 1. Fixturing was developed to hold the housing at $30^{\circ}$ with respect to a horizontal plane. The housing was assembled and solder preforms were placed in the joints between the housing components. Part of the solder preform extended from the joint and was folded upward to be parallel to the incoming laser beam. The assembled housing was then placed in the fixture such that the laser beam would be incident on the joint. The beam was positioned to have one half of the beam incident on each part of the housing and slightly offset from the housing end. The laser beam was defocused to a spot diameter of 0.084 ". When the housing was illuminated with the laser beam, the component was held stationary for 1-2 seconds to preheat the joint to the solder melting temperature and then the joint was scanned under the laser beam at a rate of $2.0 \mathrm{in.} / \mathrm{min}$. For the soldering operation, the beam was not allowed to scan over either end of the housing assembly to avoid overheating of the edges. In addition, the housing was not preheated and thermocouples were mounted inside the housings on the support rib to monitor temperature during soldering. 


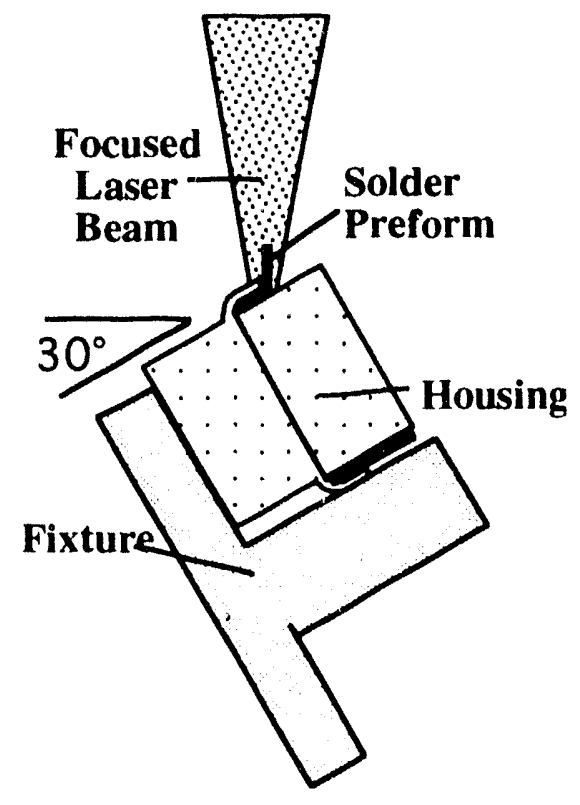

(a)

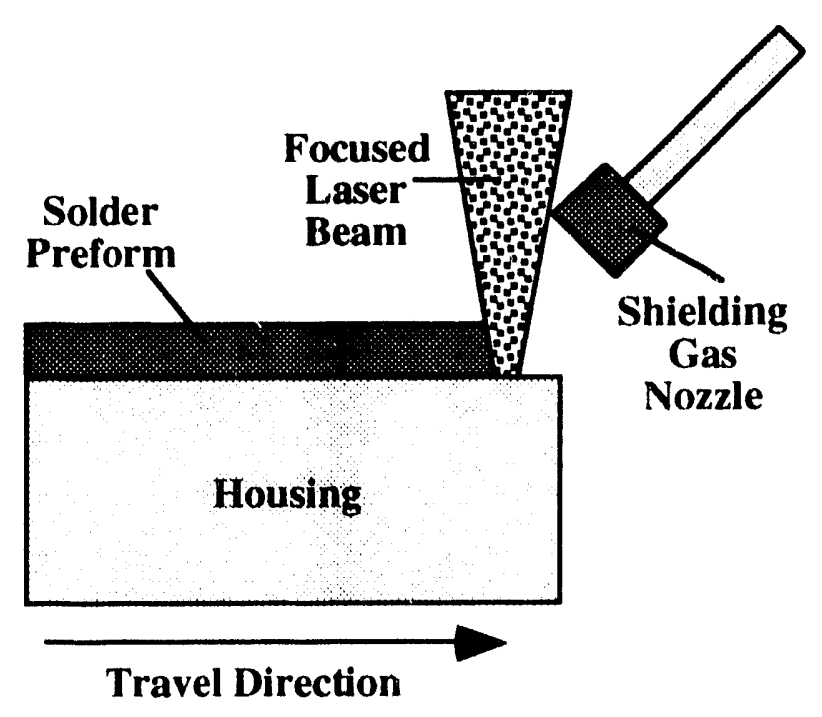

(b)

Figure 1. Experimental apparatus configuration (a) side view (b) front view.

A $60 \mathrm{Sn}-40 \mathrm{~Pb}$ wt. \% solder was used in these experiment: and tests were performed with and without solder flux. The solder was cut into a :ectangular preform with dimensions of $1.375^{\prime \prime} \times 0.320^{\prime \prime} \times 0.0025^{\prime \prime}$ which were then placed in the joint between the two housing components, Fig. 1. Initial experiments were performed without flux and only flowing a $5 \mathrm{vol} . \% \mathrm{H}_{2}$ in Ar gas around the joint to shield the molten metal from oxygen. The shielding gas was delivered to the joint from an off-axis laminar flow gas nozzle. Two empty units were also soldered using two different low solids fluxes: Kester $922 \mathrm{CX}$ and Multicore $\mathrm{X} 32 \mathrm{FQ} / 1$. The solder flux was applied sparingly, using only enough to cover the housing surfaces in the immediate area around the joint. In both of the fluxed cases, the $\mathrm{H}_{2}$ / Ar shield was utilized.

Analysis was performed to determine the integrity of the laser soldered joints and evaluate the effect of using low solids flux on extended shelf-life components. Housings soldered with both the Kester $922 \mathrm{CX}$ and Multicore X32FQ/1 low solids fluxes were sectioned metallographically in several random locations along the laser soldered seam. The results of this analysis were then used to determine the degree of wetting of the solder on both housing components. In addition, housings soldered with both of these fluxes were place in a high humidity, elevated temperature chamber for a period of 78.5 hours. The chamber was regulated to maintain $90 \%$ relative humidity at $70^{\circ} \mathrm{C}$. This environment was used to accelerate corrosion due to the solder flux residues, thus allowing evaluation of the corrosion potential for extended storage times. 
After th: initial feasibility experiments were performed, a housing containing electrical hardware was soldered. Solder joints were produced using a 1.5 second dwell and then scanning the joint under the beam at $2 \mathrm{in.} / \mathrm{min}$. with a laser power of 64 watts. After these joints were completed, the top of the housing was removed to visually determine if excessive heating occurred. It was this housing which was used in the metallographic cross-sectional analysis of the laser soldered joints.

\section{Results and Discussion}

When the $\mathrm{H}_{2}$ /Ar shielding gas without flux was used, wetting occurred between both components of the housing. Joints produced in this manner appeared partially discolored and oxidized and some areas remained along the joint where complete wetting did not occur. Manipulation of the gas nozzle to improve shielding gas coverage improved these results, although not sufficiently to produce adequate joints, i.e. with no pin holes and no oxidation.

Switching to a low solids flux, joints could be produced consistently using either of the two low solids fluxes mentioned above. Figure 2 shows a joint produced using Kester $922 \mathrm{CX}$ flux at 64 watts with a travel speed of $2 \mathrm{in} / \mathrm{min}$. and an initial dwell time of 1.5 seconds. The joint is continuous over the entire length of the housing with no apparent pin holes, Fig. 2a. In some areas, there is excess solder at the joint providing a larger than usual fillet. It was observed that the amount of excess solder was related to the width of the joint gap: in areas where the joint gap was greater the fillet remained small. A higher magnification view of a section of this joint is given in Figure 2b. Visual inspection of these joints from the inside of the housing show that the solder flowed through the joint to the inside of the housing.

Thermocouple data were used to determine the temperature excursion that the electrical components mounted in the housing would be exposed to during soldering. The measured temperature of the metal rib within the housing is given in Figure 3. The peak temperature is approximately $130^{\circ} \mathrm{C}$. This indicates that the electrical components are not heated excessively and that the heat input to the housing at the joint area is quickly dissipated due to the high thermal diffusivity of the brass. In addition, since the laser provides high efficiency heat input coupling, no preheating of the housing was required. Figure 4 shows the electrical components contained within the housing after the housing has been laser soldered. Visually, there is no obvious overheating or degradation of the polymeric materials or the solder joints used in construction. 

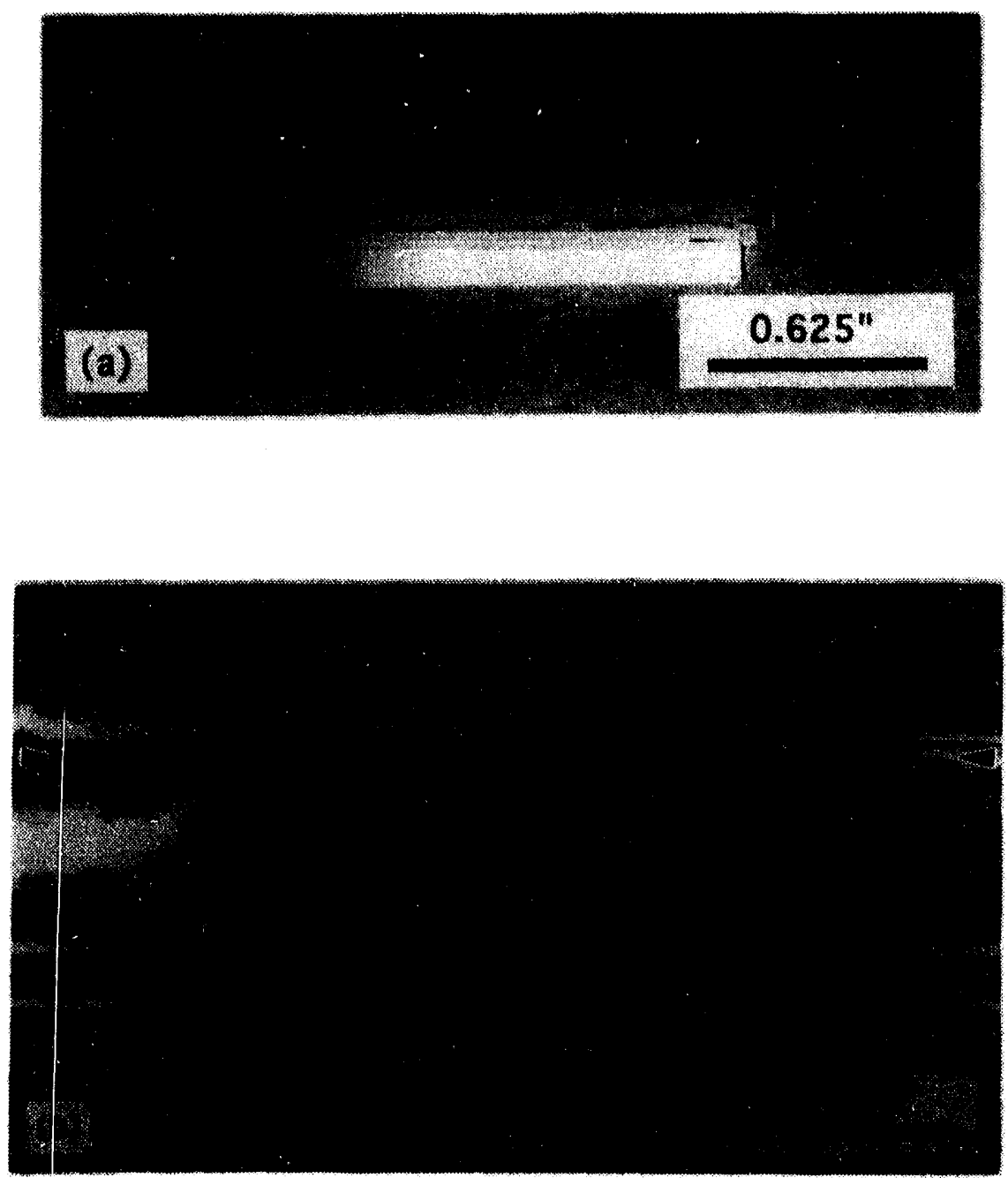

Figure 2. Photographs of laser soldered housing, 64 watts, 2 in. $/ \mathrm{min}$. travel, $1.5 \mathrm{sec}$. initial dwell time, 0.084 " laser beam spot diameter. 


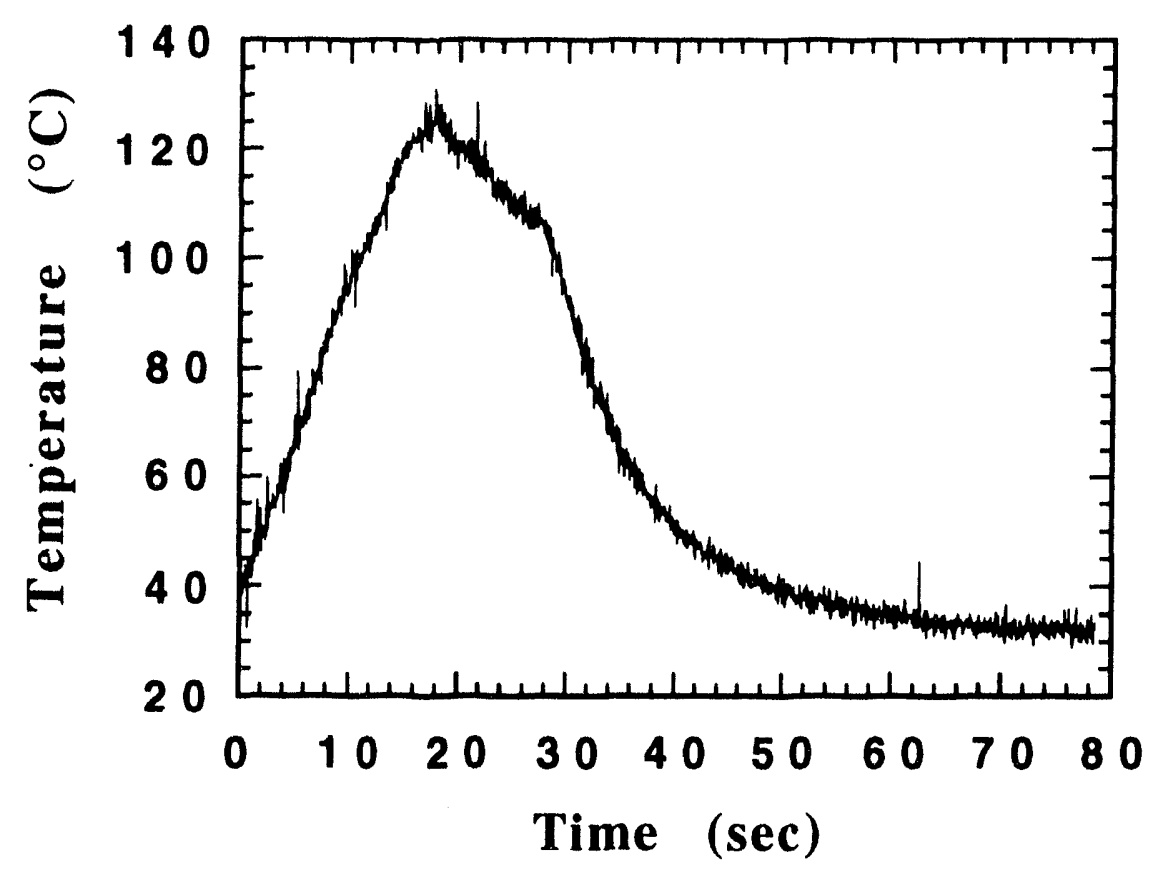

Figure 3. Temperature of housing inner rib measured during soldering operation, 64 watts, 2 in./min. travel, $1.5 \mathrm{sec}$. initial dwell time, 0.084 " laser beam spot diameter.

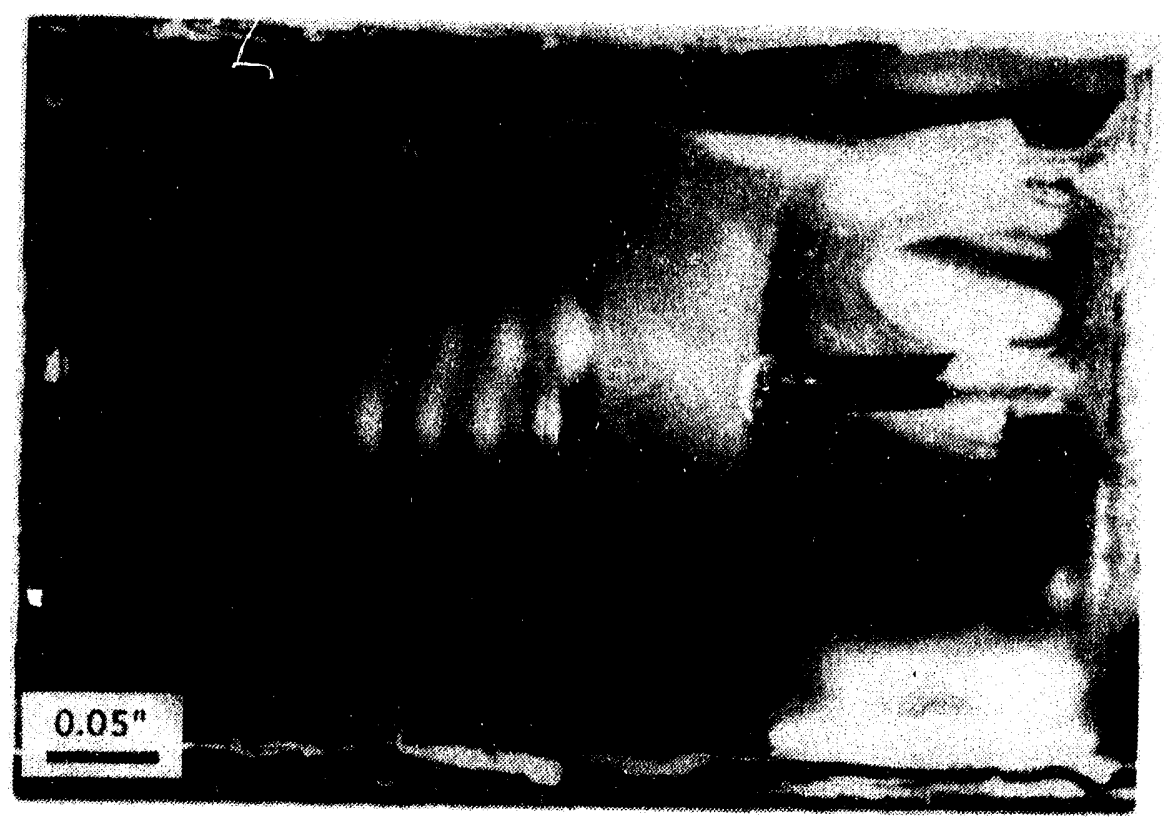

Figure 4. Photograph of electrical components within housing after soldering, 64 watts, 2 in. $/ \mathrm{min}$. travel, $1.5 \mathrm{sec}$. initial dwell time, 0.084 " laser beam spot diameter. 
Representative photomicrographs from metallographic cross-sections of laser created solder joints using both low solids fluxes are shown in Fig. 5. The crosssections for the joints made using the Kester 922CX flux (Fig. 5 a) and the Multicore $\mathrm{X} 32 \mathrm{FQ} / 1$ flux (Fig. 5 b) show very good wetting on both housing components. Other cross-sections show similar wetting characteristics, although there are small areas where the solder preform did not completely wet the substrate material. These are most likely regions where an insufficient amount of solder flux was used. As mentioned previously, solder flux was applied manually and in limited quantities. However, even with these small regions where wetting was not complete, a sufficient area was wet to provide very good electrical shielding to the components contained within the housing. None of the cross-sections displayed continuous open paths from the inside to the outside of the housings.

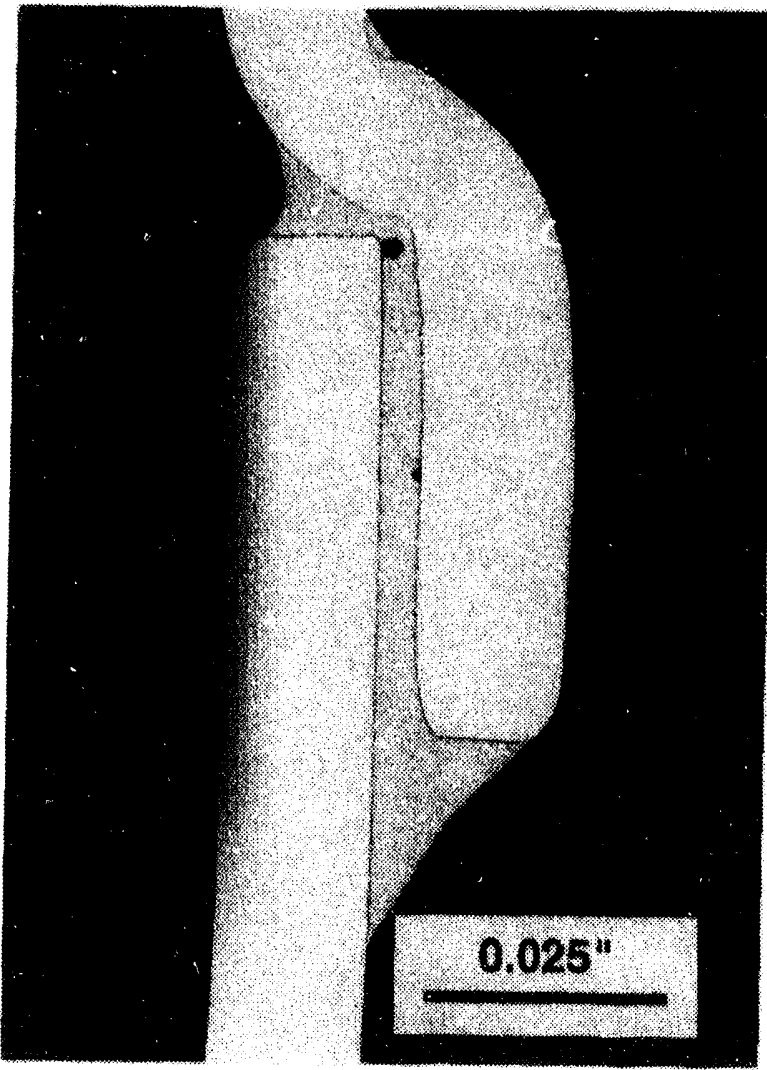

(a)

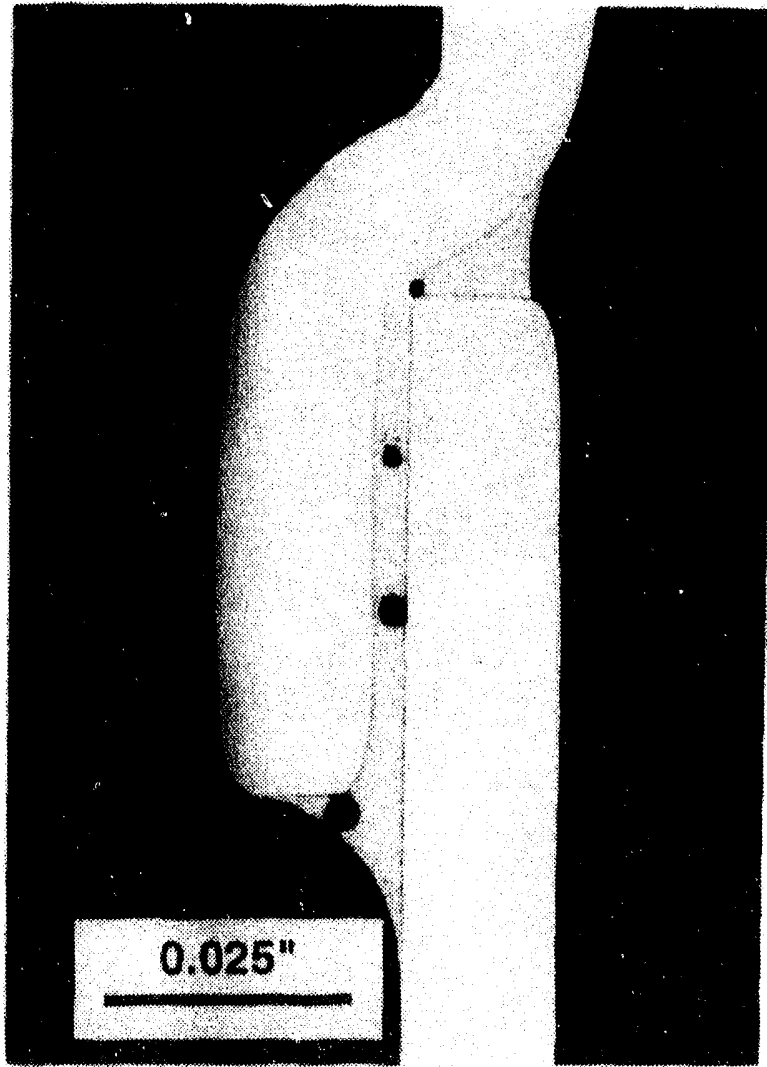

(b)

Figure 5. Photomicrograph of metallographic cross-sections for laser created solder joints on $\mathrm{Sn}$ plated brass housings, $64 \mathrm{~W}, 2.5 \mathrm{in} / \mathrm{min}$., $60-40 \mathrm{Sn}-\mathrm{Pb}$ solder, $5 \% \mathrm{H}_{2}$ in Ar shielding gas, (a) with Kester 922CX low solids solder flux, (b) with Multicore $X 32 \mathrm{FQ} / 1$ low solids solder flux. 
After removing the housings from the elevated temperature and humidity chamber, the housing surfaces were visually inspected for indications of corrosion. For housings soldered with both solder fluxes, there were some areas of discoloration. A scanning electron microscope was used to examine the discolored areas to determine if this condition was due to corrosion and, if so, determine the severity of the corrosion. Analysis of these regions showed little sign of corrosion and no pitting. These preliminary results suggest that the corrosion potential induced by this soldering process is likely to be insignificant. It should be noted that no surface analysis was performed prior to soldering of the housing or before the aging experiments.

\section{Conclusions}

The results show that laser soldering of the integrator assembly is a feasible process using a low solids soldering flux. Since this process has not been optimized, more development work is required, although the laser soldering process appears to be well suited for this application. Metallographic analysis of the solder joints shows good wetting of the solder on both components of the housing. The solder joints are continuous along the housing. The analysis also revealed no holes extending through the solder joint that could compromise the electrical shielding integrity of the closure joint. In addition, preliminary results from accelerated corrosion testing suggest that no significant corrosion potential exists with this sealing process using Kester $922 \mathrm{CX}$ or Multicore $\mathrm{X} 32 \mathrm{FQ} / 1$ low solids fluxes. Finally, preliminary results from this study and previous experimental results indicate that a fluxless laser soldering process could be developed with further work.

\section{References}

1. F. M. Hosking and D. M. Keicher, "Fluxless Soldering of Ni-Au Plated Kovar with a Laser," MRS Symposium Proc., 1991. 
Distribution:

$\begin{array}{ll}1 & 1800 \text { - A. D. Romig } \\ 1 & 1815 \text { - H. C. Peebles } \\ 1 & 1831 \text { - M. J. Cieslak } \\ 1 & 1831 \text { - F. M. Hosking } \\ 1 & 1831 \text { - F. G. Yost } \\ 10 & 1831 \text { - D. M. Keicher } \\ 1 & 1832 \text { - D. R. Frear } \\ 1 & 1832 \text { - N. R. Sorensen } \\ 1 & 1832 \text { - G. A. Poulter } \\ 1 & 1833 \text { - J. L. Jellison } \\ 1 & 2500 \text { - G. N. Beeler } \\ 1 & 2574 \text { - P. A. Smith } \\ 1 & 2574 \text { - J. F. Jones } \\ 1 & 2574 \text { - J. A. Wilder } \\ 1 & 7151 \text { - Technical Publications } \\ 5 & 7141 \text { - Technical Library } \\ 10 & 7613-2 \text { - Document Processing for DOE/OSTI } \\ 1 & 8523-2 \text { - Central Technical Files } \\ 1 & \text { P. M. Biggs, AS-KCD } \\ 1 & \text { R. J. Heinen, AS-KCD } \\ 1 & \text { T. M. Troupe, AS-KCD } \\ 1 & \text { D. E. Shepherd, AS-KCD }\end{array}$



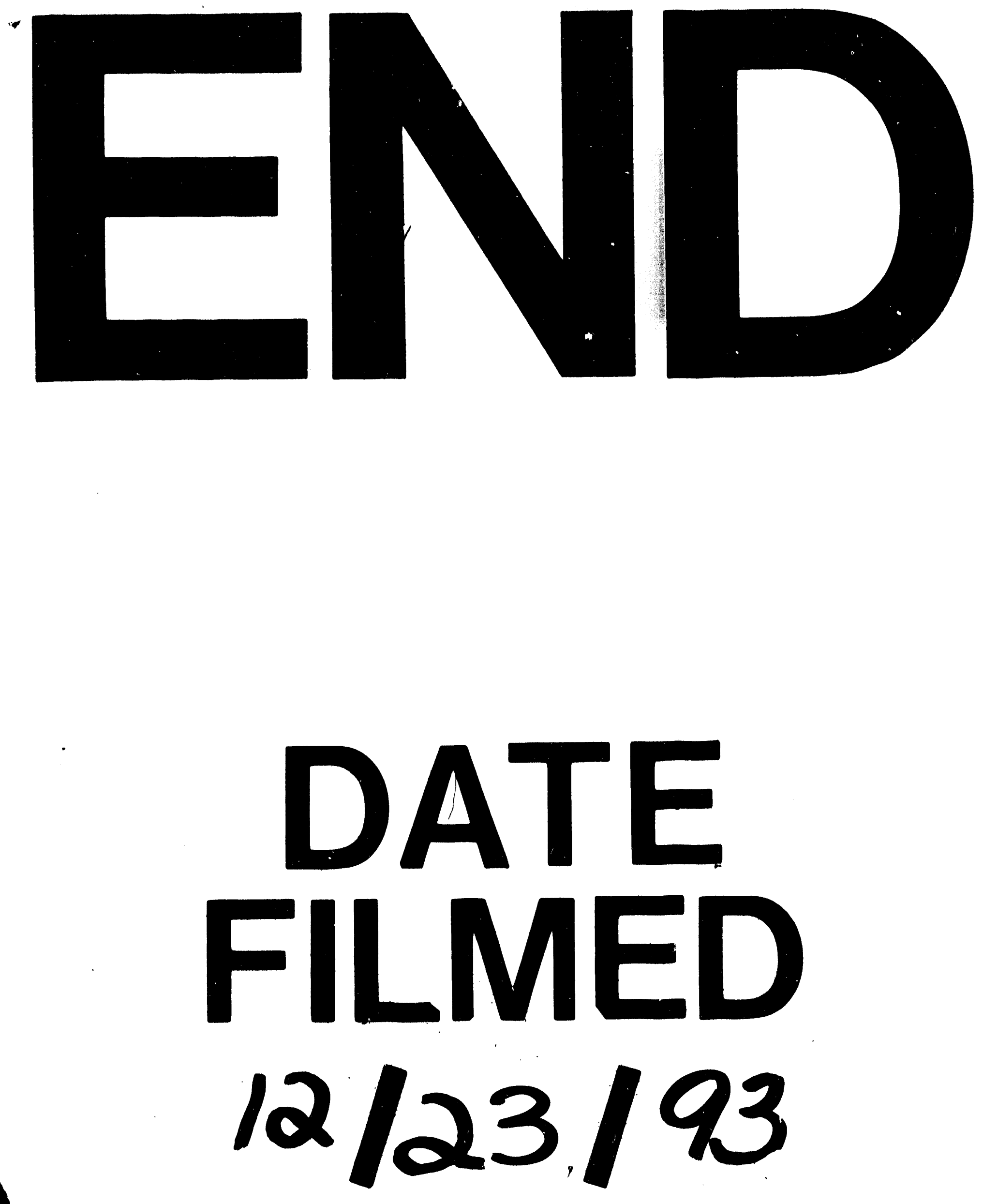

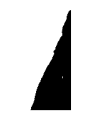


